\title{
Original article (full paper) \\ Longitudinal intra- and inter-individual variability in young swimmers' performance and determinant competition factors
}

\author{
Jorge Estrela Morais \\ Polytechnic Institute of Bragança/CIDESD, Bragança, Portugal \\ Mario J. Costa \\ Polytechnic Institute of Guarda/CIDESD, Guarda, Portugal \\ Pedro Forte \\ Polytechnic Institute of Bragança, Bragança, Portugal \\ Mario C. Marques \\ University of Beira Interior/CIDESD, Covilhã, Portugal
}

Antonio J. Silva

University of Trás-os-Montes and Alto Douro/CIDESD, Vila Real, Portugal

Daniel A. Marinho

University of Beira Interior/CIDESD, Covilhã, Portugal

Tiago M. Barbosa

Nanyang Technological University/CIDESD, Singapore

\begin{abstract}
The main purpose of this study was to follow-up the intra- and inter-individual variability of young swimmers' performance and determinant factors over two competitive seasons. Thirty young swimmers ( 14 boys: $12.33 \pm 0.65$ years -old; 16 girls: $11.15 \pm 0.55$ years-old) were followed-up throughout two consecutive seasons (seven evaluation moments). Performance (100m freestyle), anthropometric, kinematic, hydrodynamic and efficiency features were evaluated. A gender and skill-level effect was observed. Boys improved in a higher amount (\%) comparing to girls. Overall, swimmers in skill-level 2 (both genders) presented a higher intra-individual variability. Performance and anthropometrics showed a significant inter-individual variability in most moments, but hydrodynamics, kinematics and efficiency did not. Within each skill-level hydrodynamics, kinematics and efficiency were the variables that showed a high inter-individual variability. As a gender and skill-level effect was noticed in an age-group of young swimmers, coaches and practitioners should put the focus in specific and customized training plans for each skill-level of swimmers.
\end{abstract}

Keywords: young swimmers, seasons' variations, efficiency, stroke mechanics, anthropometrics

Resumo - "Análise longitudinal da variabilidade intra- e inter-individual da performance e fatores determinantes em nadadores jovens." O objetivo principal do estudo foi acompanhar a variabilidade intra- e inter-individual da performance e dos seus fatores determinantes de nadadores jovens durante duas temporadas competitivas. Trinta nadadores jovens (14 nadadores: $12.33 \pm 0.65$ anos; 16 nadadoras: $11.15 \pm 0.55$ anos) foram avaliados ao longo das duas épocas (7 momentos de avaliação). Foi avaliada a performance (100m livres), e variáveis antropométricas, cinemáticas, hidrodinâmicas e de eficiência. Foi observado um efeito do sexo e do nível competitivo. Os nadadores melhoraram em maior quantidade (\%) do que as nadadoras. Os nadadores no nível competitivo 2 (ambos os sexos) apresentaram uma intra-variabilidade superior. A performance e as variáveis antropométricas apresentaram uma inter-variabilidade significativa na maior parte dos momentos de avaliação, ao contrário das variáveis hidrodinâmicas, cinemáticas e de eficiência. Dentro de cada nível competitivo as variáveis hidrodinâmicas, cinemáticas e de eficiência foram as que apresentaram uma variabilidade inter-individual superior. Como foi verificado um efeito do sexo e do nível competitivo, treinadores e praticantes devem colocar o foco em treinos específicos e personalizados para cada grupo de nadadores de acordo com o nível competitivo.

Palavras-chave: nadadores jovens, variações sazonais, eficiência, mecânica da braçada, antropometria 


\begin{abstract}
Resumen - "Análisis longitudinal de la variabilidade intra- y inter-individual del rendimiento y sus determinantes en nadadores jóvenes." El objetivo principal del estudio fue el seguimiento de la variabilidad intra- e inter-individual del rendimiento y sus factores determinantes de nadadores jóvenes en dos temporadas competitivas. Treinta nadadores jóvenes (14 niños: $12.33 \pm 0.65$ años; 16 niñas: $11.15 \pm 0.55$ años) fueron seguidos a lo largo de dos temporadas competitivas ( 7 momentos de evaluación). Se evaluó el rendimiento (100m estilo libre), e características antropométricas, cinemáticas, hidrodinámicas e la eficiencia. Se observó un efecto del sexo e del nivel de habilidad. Los niños mejoraron en una cantidad superior (\%) en comparación con las niñas. En general, los nadadores de nivel de habilidad 2 (los dos sexos) presentaron una mayor variabilidad intra-individual. El rendimiento y la antropometría mostraron una variabilidad inter-individual significativa en la mayoría de los momentos, lo mismo no ocurrió con la hidrodinámica, la cinemática y la eficiencia. Dentro de cada nivel de habilidad, la hidrodinámica, la cinemática y la eficiencia fueron las variables que mostraron una alta variabilidad inter-individual. Como se ha observado un efecto de sexo e nivel de habilidad, entrenadores y practicantes deben poner el foco en los planes de formación específicos y personalizados para cada nivel de habilidad de los nadadores.
\end{abstract}

Palabras clave: nadadores jóvenes, variaciones estacionales, eficiencia, mecánica de la brazada, antropometría

\section{Introduction}

Competitive swimming is a multifactorial sport that performance is determined by several factors (Barbosa et al., 2010). Changes in anthropometric features influence biomechanical profile, this last ones affect energy profile and; hence the performance in both young (Morais et al., 2012; Saavedra, Escalante \& Rodríguez, 2010) and elite/adult swimmers (Barbosa et al., 2010). Follow-up studies also have reported that anthropometric traits had an effect on performance and in several stroking parameters of young swimmers within and between seasons of training (Lätt et al., 2009a; 2009b).

Earlier research was based on the universal perspective, that is, mean data is reported and analyzed. Mean data express individual changes that are shared by every subject. It is assumed a non-variance between subjects, or if this is identified, considered as being random error or noise in the dataset. Dynamical systems on movement patterns report that movement variability is driven by the interaction of the several sources of constrains (i.e., independent variables) on action leading to the uniqueness of system dynamics for a particular performer under a specific task (Davids, Glazier, Araújo, \& Bartlett, 2003). Recent research suggested that each subject should be seen as a unique individual, where a complex and dynamical athlete -environment relationship exists (Philips, Davids, Renshaw, \& Portus, 2010). Some authors report a specific and customized path in the development and maintenance of expert athletic performance (Durand-Bush \& Salmela, 2002). Therefore, individual perspective of data analysis should be a priority in sports, including swimming.

There are a few papers about variability in swimming and mainly with to adult/elite cross-sectional research (Bideault, Herault, \& Seifert, 2013; Vantorre, Seifert, Fernandes, Vilas-Boas, \& Chollet, 2010). Individual changes drift away from the average main trend very often. High intra-individual variability in energetic measures was observed for elite swimmers through consecutive seasons of training (Anderson, Hopkins, Roberts, \& Pyne, 2006; Costa et al., 2013). However, to the best of our knowledge no longitudinal research was carried out with young swimmers based on this framework (i.e., a two-year follow-up, and analyzing both intra and inter-variability). The only exception is the study of Minghelli and Castro (2006), that analyzed individual trends (mainly for kinematics) but for a shorter period of time (5 months).

Most follow-up and intervention programs reported data for pooled sample, for anthropometric or kinematic (Lätt et al., 2009a) and hydrodynamics (Marinho et al., 2010) disregarding the intra- and inter-individual variability. Therefore, performance research should give a step forward towards this type of research framework. Moreover, the variability of other determinant variables such as the body surface areas (such as hand, feet and trunk), intra-cyclic swimming velocity (dv) and arm's propelling efficiency $\left(\eta_{p}\right)$ variables remains inexistent.

The aim of this study was to assess the intra- and inter-individual variability of young swimmers' performance and its determinant factors within and between seasons according to gender and skill level. It was hypothesized an improvement of the performance and likewise of its determinant factors for each gender and skill level. Most skilled swimmers would present a higher intra- and a lower inter-variability.

\section{Methods}

\section{Participants}

Fourteen boys ( 7 in high-skill level 1: $12.83 \pm 0.37$ years of age, and 294.4 \pm 40.0 FINA points at SCM $100 \mathrm{~m}$ freestyle; 7 in average-skill level 2: $11.83 \pm 0.37$ years of age, and $166.2 \pm 17.5$ FINA points at SCM $100 \mathrm{~m}$ freestyle) and sixteen girls (8 in high-skill level 1: $11.42 \pm 0.49$ years of age, and $334.3 \pm 39.5$ FINA points at SCM $100 \mathrm{~m}$ freestyle; 8 in average-skill level 2: $10.83 \pm 0.37$ years of age, and $229.1 \pm 33.9$ FINA points at SCM $100 \mathrm{~m}$ freestyle) in Tanner stages 1-2 by self-report were evaluated. Sample includes age-group national record holders, national champions and other swimmers that are part of a national talent ID scheme. The swimmers had at the baseline $3.40 \pm 0.56$ years of training experience (total number of training sessions: 1830 in two seasons; training sessions per week: $5.09 \pm 0.87$; average volume per session: $4.86 \pm 0.97 \mathrm{~km}$ ) and participating on regular basis in regional and national level competitions. 
Coaches, parents and/or guardians and also the athletes gave their consent for participation on this study. All procedures were in accordance to the Helsinki Declaration regarding Human research. The University Institutional Review Board also approved the study design.

\section{Study design}

A longitudinal research design was carried out. The repeated and subsequent measurements throughout time can be represented by a dataset of three-dimensional axis:

$$
\eta_{\mathrm{p}}=\left[\left(\frac{\mathrm{v} \cdot 0.9}{2 \pi \cdot \mathrm{SF} \cdot \mathrm{l}}\right) \cdot \frac{2}{\pi}\right] \cdot 100
$$

where ijt represent the axis, $\mathrm{N}$ represents the number of subjects (i.e., $\mathrm{N}=30$ ), $\mathrm{M}$ represents the variables (i.e. anthropometric, kinematic, efficiency and hydrodynamic variables) and $\mathrm{T}$ represents the time measurements (seven evaluation moments over two consecutive seasons; i.e. two consecutive years). The first season evaluations occurred: M1 - 4 weeks after the beginning of the first season (first competition); M2 in the middle of the first season ( 24 weeks after the beginning); M3 - in the end of the first season (38 weeks after the beginning of the first season. A 10 weeks interval occurred between the end of the first and the beginning of the second one. In the second season: M4 - immediately before the beginning of the second season (baseline); M5 - 4 weeks after the beginning of the second season (first competition); M6 - in the middle of the second season (24 weeks after the beginning) and; M7 - in the end of the second season ( 38 weeks after the beginning). Data collection procedures were carried out always under the same conditions in all evaluation moments (e.g. the same swimming pool, lane, time of day).

\section{Performance data collection}

The official short course $100-\mathrm{m}$ freestyle race (i.e. $25 \mathrm{~m}$ length swimming pool) was selected as performance outcome. The time gap between the races and data collections took no longer than 15-days.

\section{Anthropometric data collection}

For all measurements swimmers were asked to wear only a textile swimsuit and a cap. Body surface areas were measured with digital photogrammetry (Morais et al., 2012). A 2D calibration frame and swimmers' dominant hand and foot were scanned with a copy machine (Xerox 4110, Norwalk, Connecticut, USA) to measure the hand surface area (HSA) and foot surface area (FSA) with specific software (Universal Desktop Ruler, v3.3.3268, AVPSoft, USA) (ICC: HSA=0.98; $\mathrm{FSA}=0.96$ ). As for the trunk transverse surface area (TTSA; ICC $=0.96$ ) swimmers were photographed with a digital camera (DSC-T7, Sony, Tokyo, Japan) in the transverse plane from above simulating the streamlined gliding position.

Body mass (BM) and height $(\mathrm{H})$ were measured with a digital weighting scale (SECA, 884, Hamburg, Germany) and a digital stadiometer (SECA, 242, Hamburg, Germany) respectively. Arm span (AS) and chest perimeter (CP) were measured with an anthropometric tape (RossCraft, Canada). Arm span was measured with swimmers standing on the upright position, arms and fingers fully extended laterally abducted at a $90^{\circ}$ angle. The distance between the tip of the third fingertip of each hand was measured $(\mathrm{ICC}=0.97)$. The $\mathrm{CP}$ was measured with the swimmers simulating the streamlined gliding position $(\mathrm{ICC}=0.96)$.

\section{Kinematic and efficiency data collection}

Both kinematics and efficiency were assessed during the same trials. Swimming velocity (v), stroke length (SL), stroke frequency (SF) and dv were selected as kinematic parameters. As for efficiency estimators, stroke index (SI) and $\eta_{p}$ were selected. Swimmers performed three maximal freestyle swim trials of $25 \mathrm{~m}$ with push-off start (30 minutes of recovery between bouts).

Kinematic data was collected with a speedo-meter (Swim speedo-meter, Swimsportec, Hildesheim, Germany). A 12-bit resolution acquisition card (USB-6008, National Instruments, Austin, Texas, USA) was used to transfer data (sampling rate at $50 \mathrm{~Hz}$ ) to a software customized by our group (LabVIEW ${ }^{\circledR}$ interface, v.2009) (Barbosa et al., 2013). Data were exported to a signal processing software (AcqKnowledge v.3.5, Biopac Systems, Santa Barbara, USA) and filtered with a $5 \mathrm{~Hz}$ cut-off low-pass $4^{\text {th }}$ order Butterworth filter. Swimming velocity (v, $\left.\mathrm{m} \cdot \mathrm{s}^{-1}\right)$ was computed in the middle $15 \mathrm{~m}$ as $\mathrm{v}=\mathrm{d} / \mathrm{t}$. Two expert evaluators measured the stroke frequency $\left(\mathrm{SF}\right.$, cycles $\left.\cdot \mathrm{min}^{-1}\right)$ with a frequency counter during three consecutive strokes $(\mathrm{ICC}=0.98)$ and afterwards converted to Hz. Stroke length was computed as $\mathrm{SL}=\mathrm{v} / \mathrm{SF}$ (Craig \& Pendergast, 1979). Speed fluctuation was computed as (Barbosa et al., 2010):

$$
\mathrm{dv}=\frac{\sqrt{\sum_{\mathrm{i}}\left(\mathrm{v}_{\mathrm{i}}-\overline{\mathrm{v}}\right)^{2} \mathrm{~F}_{\mathrm{i}} / \mathrm{n}}}{\sum_{\mathrm{i}} \mathrm{v}_{\mathrm{i}} \mathrm{F}_{\mathrm{i}} / \mathrm{n}}
$$

Where $\mathrm{dv}$ is the speed fluctuation (dimensionless), $\mathrm{v}$ is the mean velocity $\left(\mathrm{m} \cdot \mathrm{s}^{-1}\right), \mathrm{v}_{\mathrm{i}}$ is the instant velocity $\left(\mathrm{m} \cdot \mathrm{s}^{-1}\right), \mathrm{F}_{\mathrm{i}}$ is the absolute frequency and $\mathrm{n}$ is the number of observations. Stroke index was calculated as the product of $\mathrm{SL}$ and $\mathrm{v}(\mathrm{SI}=\mathrm{SL} * \mathrm{v})$ (Costill et al., 1985). The $\eta_{\mathrm{p}}$ was estimated as (Zamparo, Pendergast, Mollendorf, Termin, \& Minetti, 2005):

$$
\eta_{\mathrm{p}}=\left[\left(\frac{\mathrm{v} \cdot 0.9}{2 \pi \cdot \mathrm{SF} \cdot 1}\right) \cdot \frac{2}{\pi}\right] \cdot 100
$$

Where $\eta_{p}$ is the propelling efficiency (\%), $v$ is the velocity $\left(\mathrm{m} \cdot \mathrm{s}^{-1}\right), \mathrm{SF}$ is the stroke frequency $(\mathrm{Hz})$ and 1 is the distance between shoulder and tip of the $3^{\text {rd }}$ finger during the insweep $(\mathrm{m})$. 


\section{Hydrodynamic data collection}

Velocity Perturbation Method was used to estimate the active drag $\left(\mathrm{D}_{\mathrm{a}}\right)$ and the coefficient of active drag $\left(\mathrm{C}_{\mathrm{Da}}\right)$ (Kolmogorov \& Duplisheva, 1992). Swimmers performed two maximal trials of $25 \mathrm{~m}$ at front crawl with push-off start (one trial with and other without carrying on the perturbation device). Two expert evaluators with stopwatches measured the trials between the $11^{\text {th }}$ and $24^{\text {th }}$ meter (ICC $=0.97$ ) (Marinho et al., 2010). Both evaluators walked with the swimmer to have a perfect line of sight when the swimmer passed the specific point of measurement. Active drag and $\mathrm{C}_{\mathrm{Da}}$ were estimated respectively as (Kolmogorov \& Duplisheva, 1992):

$$
\begin{aligned}
& D_{a}=\frac{D_{b} v_{b} v^{2}}{v^{3}-v_{b}^{3}} \\
& C_{D a}=\frac{2 \cdot D_{a}}{\rho \cdot S \cdot v^{2}}
\end{aligned}
$$

Where $\mathrm{D}_{\mathrm{a}}$ is the swimmers' active drag at maximal velocity $(\mathrm{N}), \mathrm{D}_{\mathrm{b}}$ is the resistance of the perturbation buoy computed from the manufacturer's calibration of the buoy-drag characteristics and its velocity $(\mathrm{N}), \mathrm{v}_{\mathrm{b}}$ and $\mathrm{v}$ are the swimming velocities with and without the perturbation device $\left(\mathrm{m} \cdot \mathrm{s}^{-1}\right), \mathrm{C}_{\mathrm{Da}}$ is the active drag coefficient (dimensionless), $\rho$ is the water density (assumed to be $1000 \mathrm{~kg} \cdot \mathrm{m}^{-3}$ ), $\mathrm{v}$ is the velocity $\left(\mathrm{m} \cdot \mathrm{s}^{-1}\right.$ ) and S (or TTSA as reported in the anthropometrics sub-section) is the swimmers' projected frontal surface area $\left(\mathrm{cm}^{2}\right)$.

\section{Statistical analysis}

Normality and homocedasticity assumptions were analyzed with the Kolmogorov-Smirnov and Levene tests, respectively. Intra-individual data variation was analyzed with ANOVA three-ways for all selected variables (time, gender and skill effects and interactions) followed by the Bonferroni post-hoc test ( $p$ $\leq .05$ ). Intra-individual differences between moments within and between seasons $(\Delta$, in \%) were also calculated for each skill-level (skill-level 1: highest; skill-level 2: average). Total eta square $\left(\mathrm{h}^{2}\right)$ was selected as effect size index and interpreted as: (i) without effect if $0<\mathrm{h}^{2} \leq 0.04$; (ii) minimum if $0.04<\mathrm{h}^{2} \leq$ 0.25 ; (iii) moderate if $0.25<\mathrm{h}^{2}<0.64$ and; (iv) strong if $\mathrm{h}^{2}>0.64$.

The $t$-student test for independent sample was used to assess inter-individual variability between skill-level in each gender ( $p$ $\leq .05)$. The Cohen's Kappa, delimited by the percentiles 33, 66 and 100 was used to detect the boys and girls' inter-variability within each sports level. Kappa plus 95\% confidence interval was computed with the Longitudinal Data Analysis software (v.3.2, Dallas, USA). The qualitative interpretation was done as (Landis \& Koch, 1977): excellent if $\mathrm{K} \geq 0.75$; (ii) moderate if $0.40 \leq \mathrm{K}<0.75$ and; (iii) low if $\mathrm{K}<0.40$ based on the stability (i.e. higher stability means lower inter-individual variability).

\section{Results}

Overall data presented a significant time effect for all variables but the SF (Table 1). Also a significant gender effect was showed for most variables, except the $\mathrm{C}_{\mathrm{Da}}, \mathrm{dv}$ and $\eta_{\mathrm{p}}$. The skill-level effect showed the same trend, except for the FSA, $\mathrm{C}_{\mathrm{Da}}, \mathrm{SF}$ and $\mathrm{dv}$.

\begin{tabular}{|c|c|c|c|c|c|c|c|c|c|c|c|c|}
\hline & \multicolumn{3}{|c|}{ Time Effect } & \multicolumn{3}{|c|}{ Gender Effect } & \multicolumn{3}{|c|}{ Skill level Effect } & \multicolumn{3}{|c|}{$\begin{array}{l}\text { Time x Gender x Skill } \\
\text { level Interaction }\end{array}$} \\
\hline & $F$ & $p$ & $\eta^{2}$ & $F$ & $p$ & $\eta^{2}$ & $F$ & $p$ & $\eta^{2}$ & $F$ & $p$ & $\eta^{2}$ \\
\hline BM [kg] & 125.96 & $<.001$ & 0.95 & 10.29 & .004 & 0.20 & 13.78 & .001 & 0.27 & 0.41 & .74 & 0.003 \\
\hline $\mathrm{H}[\mathrm{cm}]$ & 136.90 & $<.001$ & 0.78 & 12.80 & .001 & 0.25 & 11.48 & .002 & 0.22 & 0.87 & .40 & 0.004 \\
\hline $\mathrm{AS}[\mathbf{c m}]$ & 143.99 & $<.001$ & 0.78 & 20.67 & $<.001$ & 0.34 & 12.72 & .001 & 0.21 & 0.78 & .45 & 0.004 \\
\hline $\mathrm{CP}[\mathrm{cm}]$ & 96.98 & $<.001$ & 0.77 & 7.52 & .01 & 0.14 & 16.99 & $<.001$ & 0.33 & 0.35 & .80 & 0.002 \\
\hline TTSA $\left[\mathrm{cm}^{2}\right]$ & 24.72 & $<.001$ & 0.47 & 4.45 & .04 & 0.10 & 11.68 & .002 & 0.27 & 0.27 & .86 & 0.005 \\
\hline HSA $\left[\mathrm{cm}^{2}\right]$ & 171.48 & $<.001$ & 0.84 & 31.85 & $<.001$ & 0.43 & 13.90 & .001 & 0.18 & 0.22 & .87 & 0.001 \\
\hline FSA $\left[\mathbf{c m}^{2}\right]$ & 79.53 & $<.001$ & 0.74 & 24.03 & $<.001$ & 0.43 & 3.60 & .069 & 0.06 & 0.33 & .74 & 0.003 \\
\hline $\mathrm{SF}[\mathrm{Hz}]$ & 1.51 & .21 & 0.04 & 10.71 & .003 & 0.28 & 1.14 & .29 & 0.03 & 1.94 & .11 & 0.06 \\
\hline SL [m] & 42.80 & $<.001$ & 0.59 & 4.71 & .03 & 0.08 & 23.78 & $<.001$ & 0.42 & 0.77 & .52 & 0.01 \\
\hline $\mathbf{v}\left[\mathbf{m} \cdot \mathbf{s}^{-1}\right]$ & 68.50 & $<.001$ & 0.70 & 44.77 & $<.001$ & 0.49 & 16.79 & $<.001$ & 0.18 & 0.58 & .63 & 0.005 \\
\hline dv [dimensionless] & 2.78 & .05 & 0.09 & 1.65 & .21 & 0.05 & 0.31 & .57 & 0.01 & 0.54 & .63 & 0.01 \\
\hline $\mathbf{D}_{\mathrm{a}}[\mathbf{N}]$ & 17.82 & $<.001$ & 0.39 & 7.82 & .01 & 0.18 & 7.23 & .01 & 0.17 & 0.09 & .96 & 0.002 \\
\hline $\mathrm{C}_{\mathrm{Da}}$ [dimensionless] & 11.35 & $<.001$ & 0.26 & 0.53 & .47 & 0.01 & 0.007 & .93 & 0.00 & 0.60 & .65 & 0.01 \\
\hline$\eta_{p}[\%]$ & 30.79 & $<.001$ & 0.50 & 1.36 & .25 & 0.04 & 5.89 & .02 & 0.17 & 0.60 & .65 & 0.009 \\
\hline $\mathrm{SI}\left[\mathrm{m}^{2} \cdot \mathbf{s}^{-1}\right]$ & 63.22 & $<.001$ & 0.68 & 29.36 & $<.001$ & 0.31 & 33.50 & $<.001$ & 0.36 & 0.42 & .74 & 0.004 \\
\hline Perf@100free [s] & 106.92 & $<.001$ & 0.69 & 35.87 & $<.001$ & 0.33 & 40.97 & $<.001$ & 0.38 & 1.23 & .30 & 0.007 \\
\hline
\end{tabular}

Table 1. Data variation (ANOVA 3-way) during the two competitive seasons for total group of swimmers.

BM - body mass; AS - arm span; H - height; CP - chest perimeter; TTSA - trunk transverse surface area; HSA - hand surface area; FSA - foot surface area; D - active drag; $\mathrm{C}_{\mathrm{Da}}$ - active drag coefficient; SF - stroke frequency; SL - stroke length; $v$ - swimming velocity; dv - speed fluctuation; $\eta_{\mathrm{p}}-$ propelling efficiency; $\mathrm{SI}$ - stroke index; Perf - performance; $\eta^{2}$ - effect size. 
Performance improved significantly for the two genders in both skill-levels between initial and final moment (Figure 1). For both genders, the swimmers in the skill-level 2 presented a higher intra-individual variability (i.e. higher amount of improvement) between consecutive moments (within season) and also in homologous ones (between seasons) (Table 2A,B). Anthropometrics presented a similar trend as most variables increased significantly between initial and final moment. The skill-level 2 swimmers were the ones with the highest variability (Figure 2, Table 2 A,B). Hydrodynamics also increased between initial and final moment but not significantly for both consecutive and homologous moments (Figure 2, Table 2A,B). Boys' skill-level 2 presented the highest intra-individual variability (within and between seasons) in comparison to boys' skill-level 1 (Table 2A). As for the girls, an inverse trend was observed in consecutive moments (within) but similar in homologous ones (Table 2B). Kinematics and efficiency improved between initial and final moment, being significant only for the swimming velocity. For both boys and girls, the skill-level 2 presented the highest amount of intra-individual variability. Overall for all variables, swimmers (both genders) in skill-level 2 presented a higher intra-variability.

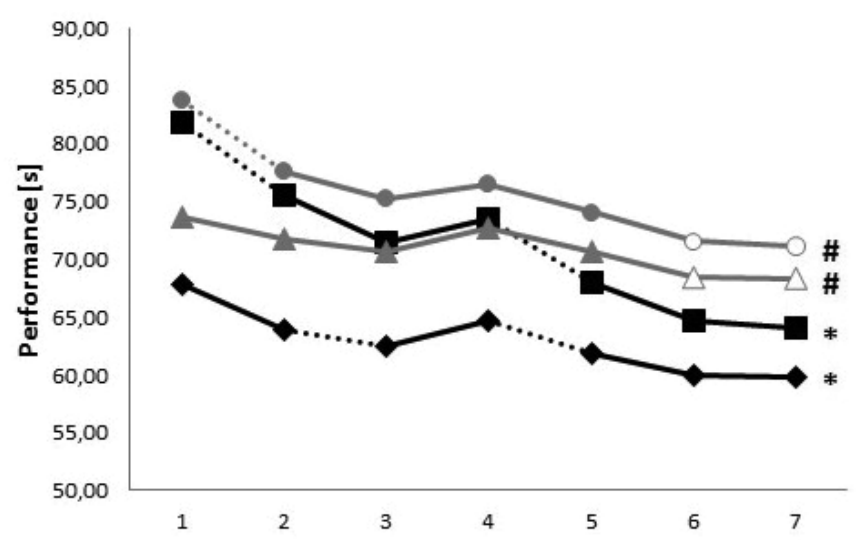

Figure 1. Performance variability along the two seasons. Black solid line $(\bullet)(\boldsymbol{\bullet})$ - boys sports level 1 and 2 respectively; grey solid line $(\boldsymbol{\Delta})(\bullet)$ girls sports level 1 and 2 respectively; dot parts within solid line means significant differences $(p \leq .05)$ between moments for each sports level; white background in the marker - no-significant differences $(p>.05)$ between sports level within each gender; PERF-performance@100free; $*$ and \# after each sports level line - significant differences $(p \leq .05)$ between initial (1) and final moment (7) for boys and girls, respectively.

Table 2A. Intra-individual differences (\%) between consecutive and homologous moments for boys (1: high-skill level vs 2: average-skill level).

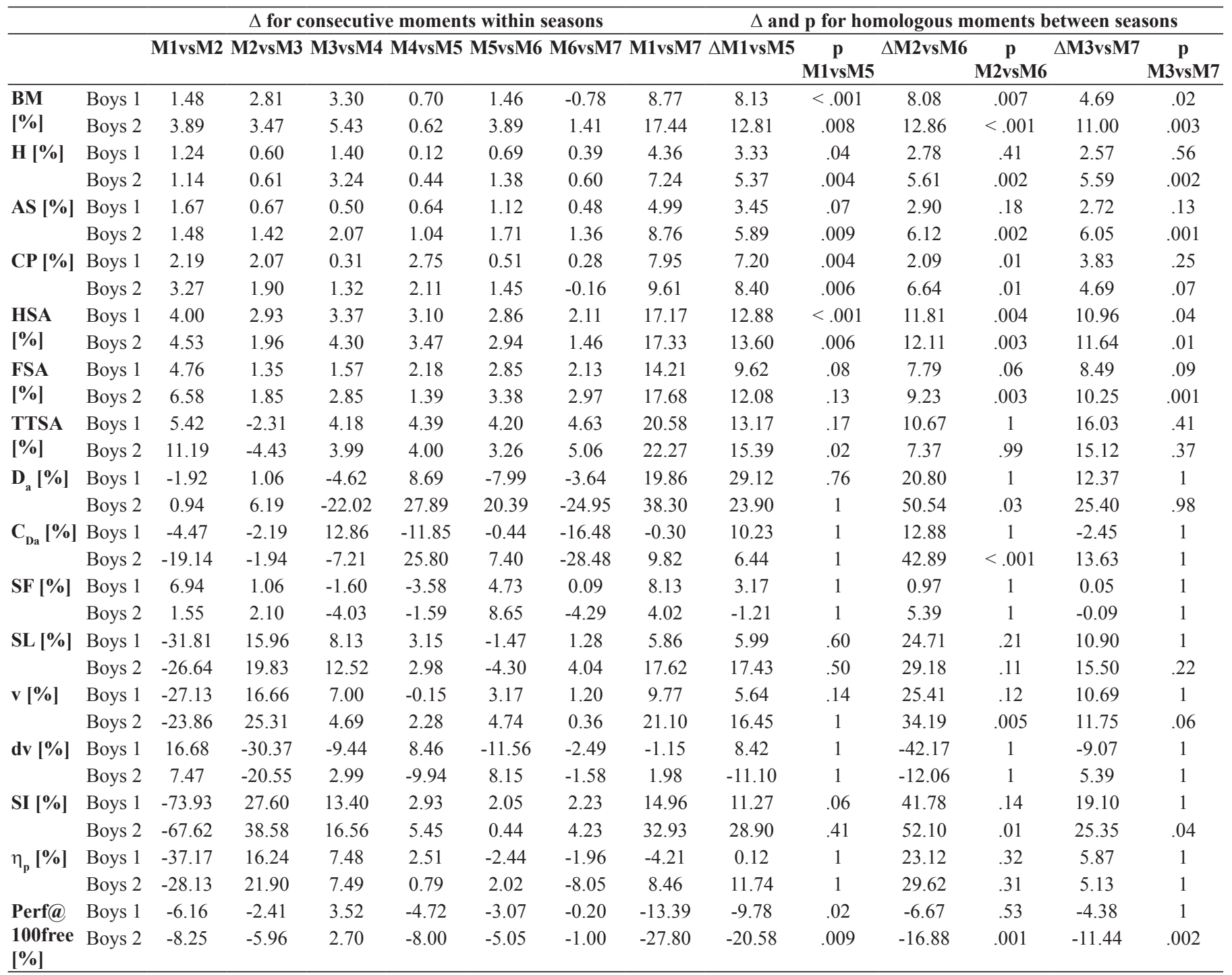


Table 2B. Intra-individual differences (\%) between consecutive and homologous moments for girls (1: high-skill level vs 2: average-skill level).

\begin{tabular}{|c|c|c|c|c|c|c|c|c|c|c|c|c|c|c|}
\hline & & \multicolumn{7}{|c|}{$\Delta$ for consecutive moments within seasons } & \multicolumn{6}{|c|}{$\Delta$ and $P$ for homologous moments between seasons } \\
\hline & & M1vsM2 & M2vsM3 & M3vsM4 & M4vsM5 & M5vsM6 & M6vsM7 & M1vsM7 & $\Delta$ M1vsM5 & p & $\Delta$ M2vsM6 & $\mathbf{p}$ & $\Delta$ M3vsM7 & p \\
\hline & & & & & & & & & & M1vsM5 & & M2vsM6 & & M3vsM7 \\
\hline \multirow{2}{*}{$\begin{array}{l}\text { BM } \\
{[\%]}\end{array}$} & Girls 1 & -0.18 & 2.86 & 3.69 & 1.51 & 1.77 & 0.26 & 9.71 & 7.85 & $<.001$ & 9.58 & .009 & 7.14 & .07 \\
\hline & Girls 2 & 1.39 & 4.59 & 3.94 & 1.70 & 3.07 & 2.41 & 16.00 & 11.20 & .02 & 12.65 & .01 & 10.66 & .03 \\
\hline \multirow[t]{2}{*}{ H [\%] } & Girls 1 & 1.08 & 0.34 & 1.15 & 0.54 & 0.39 & 0.34 & 3.80 & 3.09 & .002 & 2.41 & .01 & 2.41 & .08 \\
\hline & Girls 2 & 1.30 & 1.14 & 1.63 & 0.61 & 1.12 & 0.43 & 6.09 & 4.62 & $<.001$ & 4.43 & .002 & 3.76 & .004 \\
\hline \multirow[t]{2}{*}{ AS [\%] } & Girls 1 & 1.60 & 1.13 & 0.54 & 0.57 & 0.54 & 0.26 & 4.57 & 3.80 & .02 & 2.76 & .01 & 1.90 & .09 \\
\hline & Girls 2 & 2.45 & 1.28 & 1.02 & 0.76 & 2.01 & 0.65 & 7.92 & 5.41 & .001 & 4.99 & .001 & 4.39 & .001 \\
\hline \multirow[t]{2}{*}{ CP [\%] } & Girls 1 & 2.26 & 1.60 & 0.63 & 2.58 & 1.56 & -0.56 & 7.89 & 6.92 & .008 & 6.26 & .01 & 4.22 & .06 \\
\hline & Girls 2 & 2.85 & 1.84 & 0.82 & 3.02 & 2.48 & 0.80 & 11.31 & 8.30 & .008 & 7.91 & .03 & 6.95 & .04 \\
\hline \multirow{2}{*}{$\begin{array}{l}\text { HSA } \\
{[\%]}\end{array}$} & Girls 1 & 5.80 & 1.86 & 2.64 & 1.93 & 2.15 & 2.19 & 15.51 & 11.70 & .007 & 8.35 & .001 & 8.61 & .01 \\
\hline & Girls 2 & 6.09 & 2.19 & 2.23 & 3.46 & 1.61 & 2.23 & 16.64 & 13.26 & .009 & 9.20 & .004 & 9.25 & .002 \\
\hline \multirow{2}{*}{$\begin{array}{l}\text { FSA } \\
{[\%]}\end{array}$} & Girls 1 & 4.24 & 5.53 & 3.50 & 1.40 & 1.56 & 1.56 & 16.46 & 13.75 & .11 & 11.50 & .01 & 7.80 & .02 \\
\hline & Girls 2 & 6.20 & 2.95 & 3.25 & 2.75 & 1.72 & 1.17 & 16.92 & 14.43 & .05 & 10.26 & .02 & 8.64 & .02 \\
\hline \multirow{2}{*}{$\begin{array}{l}\text { TTSA } \\
{[\%]}\end{array}$} & Girls 1 & 6.91 & -4.04 & 3.02 & 2.98 & 3.53 & 3.00 & 15.89 & 10.22 & 1 & 5.72 & 1 & 11.75 & .59 \\
\hline & Girls 2 & 7.76 & 1.53 & 4.31 & 0.07 & 2.50 & 6.29 & 22.14 & 14.71 & .006 & 8.69 & 1 & 13.33 & .26 \\
\hline \multirow[t]{2}{*}{$D_{\mathrm{a}}[\%]$} & Girls 1 & -8.19 & 8.75 & -4.88 & 43.23 & -20.97 & -6.42 & 43.80 & 50.58 & .009 & 47.08 & .12 & 42.88 & .05 \\
\hline & Girls 2 & -5.14 & 13.96 & -2.95 & 34.17 & 26.38 & -104.57 & 37.82 & 50.24 & .003 & 63.67 & .04 & 30.96 & 1 \\
\hline \multirow[t]{2}{*}{$\mathrm{C}_{\mathrm{Da}}[\%]$} & Girls 1 & -21.91 & 11.71 & 22.85 & 17.11 & -25.10 & -9.05 & 38.60 & 52.74 & .001 & 48.17 & .14 & 42.69 & .11 \\
\hline & Girls 2 & -34.26 & 2.11 & 8.37 & 28.82 & 26.27 & -106.57 & 26.18 & 33.96 & .04 & 54.27 & .08 & 32.98 & 1 \\
\hline \multirow[t]{2}{*}{ SF [\%] } & Girls 1 & -3.02 & -1.40 & -1.58 & 3.05 & -0.44 & 2.26 & -0.71 & -2.23 & 1 & 0.52 & 1 & 3.95 & 1 \\
\hline & Girls 2 & 4.37 & -1.00 & 4.88 & -3.85 & -4.78 & 0.89 & 2.50 & 5.50 & 1 & -3.09 & 1 & -1.42 & 1 \\
\hline \multirow[t]{2}{*}{ SL [\%] } & Girls 1 & -38.39 & 20.33 & 15.69 & -3.63 & 6.09 & -3.31 & 10.52 & 8.20 & 1 & 37.25 & $<.001$ & 16.95 & .09 \\
\hline & Girls 2 & -18.41 & 15.80 & 5.67 & 5.17 & 8.50 & -1.36 & 21.57 & 15.35 & .20 & 32.38 & .01 & 17.98 & .21 \\
\hline \multirow[t]{2}{*}{ v [\%] } & Girls 1 & -38.14 & 18.26 & 14.34 & 0.70 & 6.03 & -0.72 & 13.52 & 8.47 & .24 & 36.63 & $<.001$ & 19.41 & .27 \\
\hline & Girls 2 & -12.90 & 17.75 & 9.85 & 2.34 & 4.97 & -0.35 & 23.86 & 19.98 & .18 & 31.65 & .001 & 16.35 & .02 \\
\hline \multirow[t]{2}{*}{ dv [\%] } & Girls 1 & -9.36 & -11.87 & -10.84 & -6.95 & -13.03 & -11.54 & -62.35 & -38.41 & 1 & -39.32 & 1 & -37.48 & .13 \\
\hline & Girls 2 & 3.14 & 1.56 & -6.08 & -7.11 & -12.04 & -18.41 & -36.15 & -9.15 & 1 & -18.46 & 1 & -46.55 & .49 \\
\hline \multirow[t]{2}{*}{ SI [\%] } & Girls 1 & -93.96 & 32.66 & 25.21 & -2.67 & 11.77 & -3.61 & 23.36 & 16.11 & .23 & 59.87 & $<.001$ & 32.03 & .07 \\
\hline & Girls 2 & -39.90 & 29.23 & 13.46 & 7.72 & 12.94 & -1.87 & 38.95 & 31.11 & .08 & 52.54 & .003 & 30.54 & .06 \\
\hline \multirow[t]{2}{*}{$\eta_{p}[\%]$} & Girls 1 & -36.05 & 20.25 & 16.31 & -5.08 & 10.89 & -7.44 & 13.33 & 9.50 & .64 & 40.68 & .001 & 18.79 & .50 \\
\hline & Girls 2 & -21.08 & 17.94 & 5.76 & 3.17 & 14.89 & -13.62 & 17.64 & 13.93 & .08 & 37.52 & .005 & 13.46 & .56 \\
\hline \multirow{2}{*}{$\begin{array}{l}\text { Perf@ } \\
\text { 100free } \\
{[\%]}\end{array}$} & Girls 1 & -2.66 & -1.72 & 2.91 & -2.82 & -3.40 & -0.14 & -7.77 & -4.17 & .22 & -4.91 & .14 & -3.30 & 1 \\
\hline & Girls 2 & -8.01 & -3.05 & 1.71 & -3.44 & -3.60 & -0.61 & -17.85 & -13.11 & .01 & -8.40 & .006 & -5.91 & .21 \\
\hline
\end{tabular}

BM - body mass; AS - arm span; H - height; CP - chest perimeter; TTSA - trunk transverse surface area; HSA - hand surface area; FSA - foot surface area; $\mathrm{D}_{\mathrm{a}}$ - active drag; $\mathrm{C}_{\mathrm{Da}}$ - active drag coefficient; $\mathrm{SF}$ - stroke frequency; $\mathrm{SL}$ - stroke length; $\mathrm{v}$ - swimming velocity; dv - speed fluctuation; $\eta_{\mathrm{p}}$ - propelling efficiency; SI - stroke index; Perf - performance; $\mathrm{M}$ - moment; $\Delta$ - delta value; $p$ - significant value; $\%$ - percentage.

Performance data showed a significant inter-individual variability between skill-levels within both genders in most moments (Figure 1). Anthropometric features also showed a significant inter-individual variability except in the last moments stage of the second season (M6 and M7) (Figure 2). The FSA presented no-significant inter-individual variability in all moments for both genders. As for hydrodynamics, kinematics and efficiency the main trend was the no-significant inter-individual variability in both genders and skill -levels. The exception was the $\mathrm{v}$ that presented significant inter-individual variability between skill-levels in several moments, mainly for the boys (Figures 2 and 3). Overall, an inverse trend was found for anthropometrics (significant) and remaining domains (no-significant) between skill-levels for both genders.

Performance presented a moderate $(0.40 \leq \mathrm{K}<0.75)$ inter-individual variability in each gender and skill-level, except for boys in the skill-level 2 (high, $\mathrm{K}=0.24$ ). Hydrodynamics, kinematics and efficiency showed a high inter-individual variability in both genders and skill-levels (except the SF for the boys' skill-level 1: low, $\mathrm{K}=0.66$ ). Overall, it seems that a high inter-individual variability exists within each skill-level. 

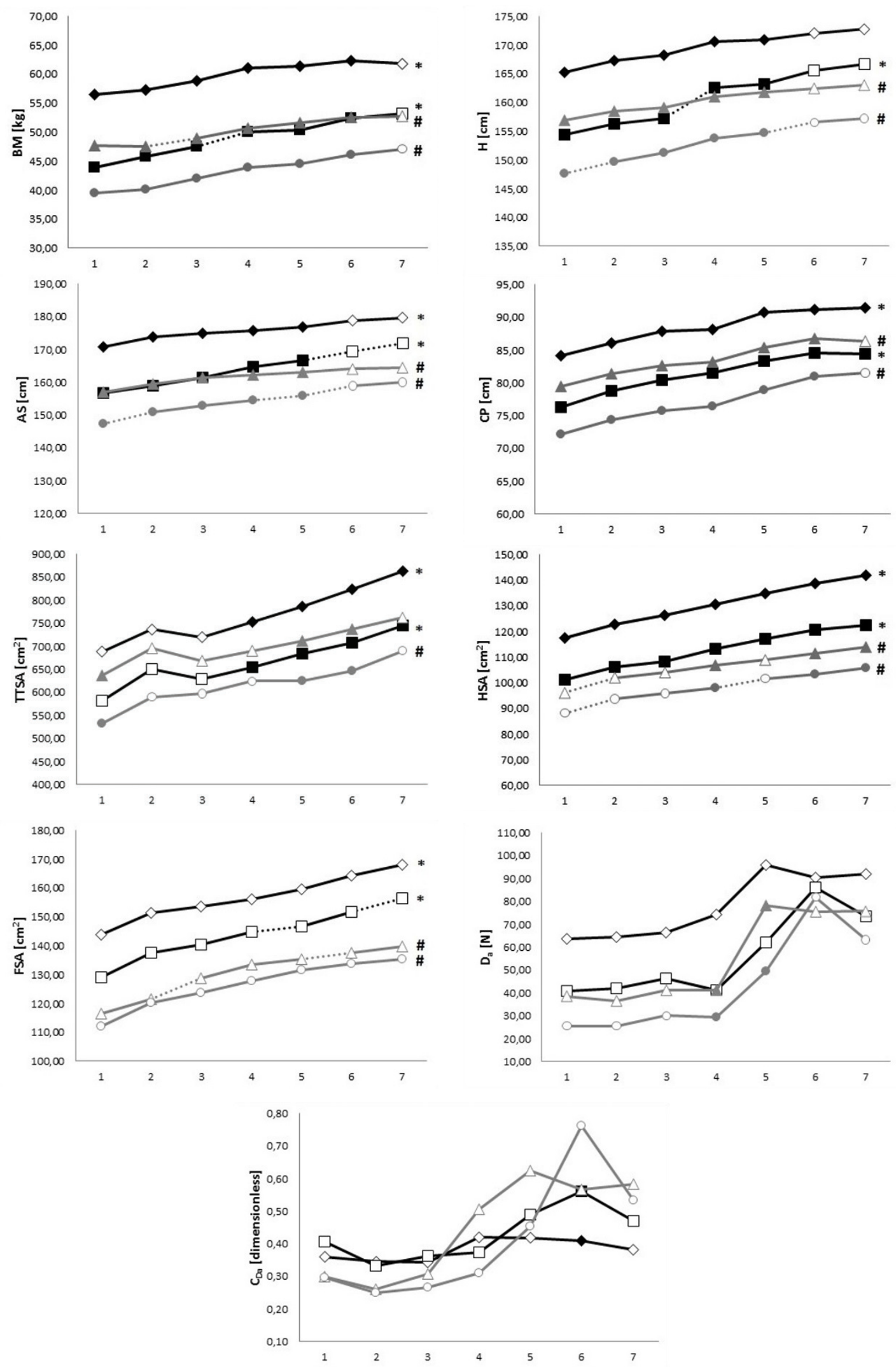

Figure 2. Anthropometric and hydrodynamic variability along the two seasons. Black solid line ( $\bullet)(\boldsymbol{\square})$ - boys sports level 1 and 2 respectively; grey solid line $(\boldsymbol{\Delta})(\bullet)$ - girls sports level 1 and 2 respectively; dot parts within solid line means significant differences $(p \leq .05)$ between moments for each sports level; white background in the marker - no-significant differences $(\mathrm{P}>0.05)$ between sports level within each gender; $\mathrm{BM}-$ body mass; AS - arm span; H - height; CP - chest perimeter; TTSA - trunk transverse surface area; HSA - hand surface area; FSA - foot surface area; $\mathrm{D}_{\mathrm{a}}$ - active drag; $\mathrm{C}_{\mathrm{Da}}$ - active drag coefficient; * and \# after each sports level line - significant differences $(p \leq .05)$ between initial (1) and final moment (7) for boys and girls, respectively. 

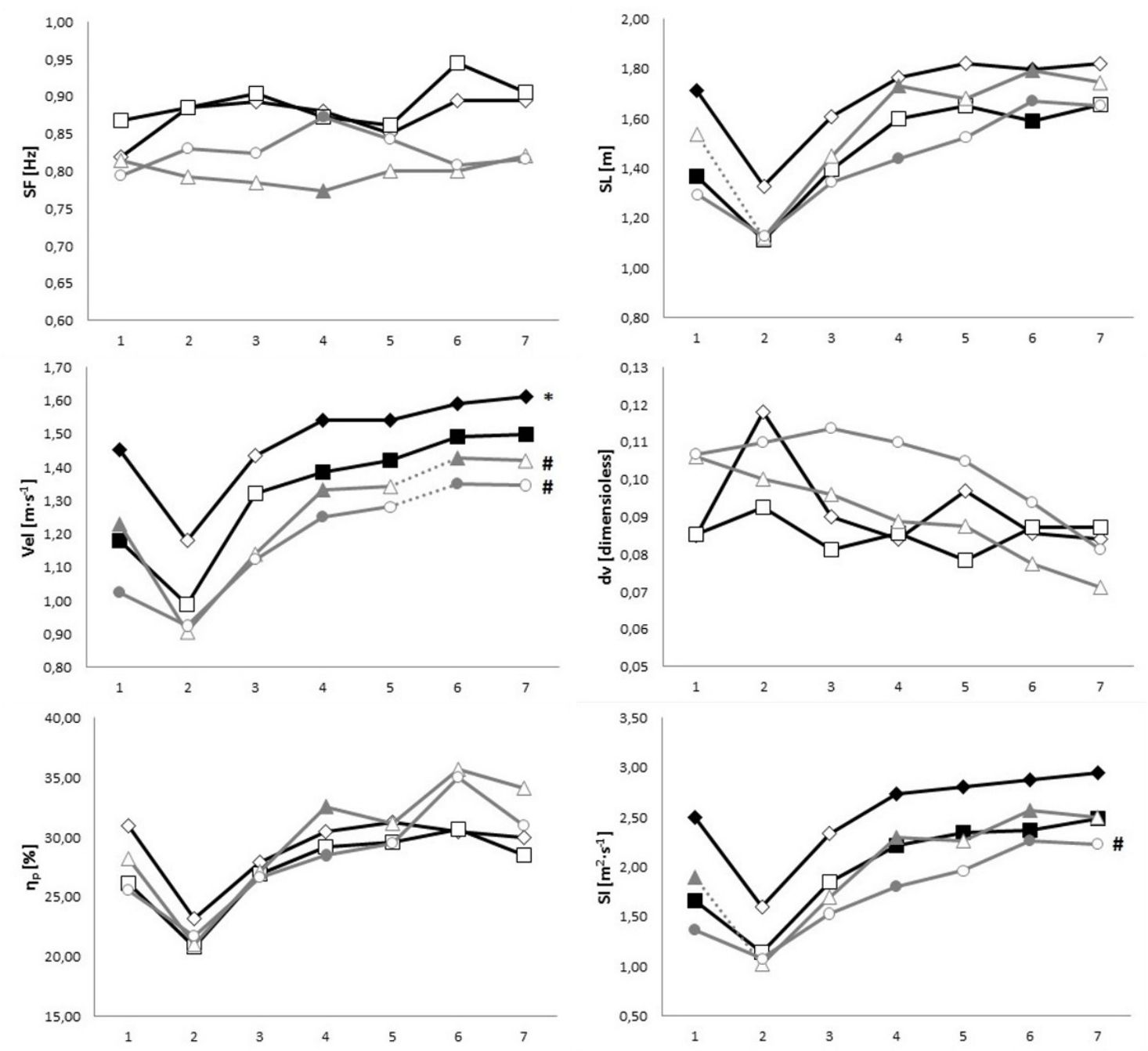

Figure 3. Kinematic and energetic variability along the two seasons. Black solid line ( $\downarrow)(\boldsymbol{\bullet})$ - boys sports level 1 and 2 respectively; grey solid line $(\boldsymbol{\Delta})(\bullet)$ - girls sports level 1 and 2 respectively; dot parts within solid line means significant differences $(p \leq .05)$ between moments for each sports level; white background in the marker - no-significant differences $(p>.05)$ between sports level within each gender; SF - stroke frequency; $\mathrm{SL}$ - stroke length; $v$ - swimming velocity; $d v$ - speed fluctuation; $\eta_{\mathrm{p}}$ - propelling efficiency; SI - stroke index; * and \# after each sports level line - significant differences $(p \leq .05)$ between initial (1) and final moment (7) for boys and girls, respectively.

\section{Discussion}

The aim of this study was to assess the intra- and inter-individual variability of young swimmers' performance and its determinant factors within and between seasons according to gender and skill -level. Main findings were the significant gender and skill-level (both genders) effects. Swimmers in skill-level 2 presented a higher intra-individual variability in comparison to skill-level 1. Overall, a significant inter-individual variability between skill-levels (both genders) was found for performance and anthropometrics but not for hydrodynamics, kinematics and efficiency.

\section{Intra-individual variability}

Performance showed a significant improvement between first (M1) and last (M7) evaluations in both genders and skill-levels. Previous studies also pointed out a performance improvement for young swimmers during two consecutive years (Lätt et al., 2009a; 2009b; Tella, Llana, Madera, \& Navarro, 2002). However, these studies plotted all swimmers only by gender and did not have into account the hypothetical differences between swimmers of the same gender. Present data shows that swimmers in the same agegroup have different rates of performance enhancement (Figure 1 , Table 2A,B). Regarding the gender gap, boys improved more sharply their performance than girls when comparing homologous skill-levels (skill-level 1 boys vs. girls: $-13.39 \%$ vs. $-7.77 \%$; skill-level 2 boys $v s$. girls: $-27.80 \%$ vs. $-17.85 \%$ ). And swimmers in skill-level 2 (both genders) showed a higher intra-individual variability in comparison to the ones in skill-level 1 . The delayed maturation in boys in comparison to girls may explain the gender gap and therefore the higher amount of performance improvement. And it might be speculated that swimmers in skill-level 2 (both genders) were also in a less mature phase, increasing their chances to enhance the performance.

All anthropometric variables (i.e. lengths and body surfaces) increased between M1 and M7 for both genders' skill-levels, and most of them significantly (Figure 2, Table 2A,B). Young 
swimmers, as any other children, experience physical changes as part of their normal biological development. Body mass, height, and therefore, limbs' lengths and areas are some of the anthropometric features that change with growth (Malina \& Bouchard, 1991). Overall, growth rate was similar or higher in boys than in girls. These data suggested that boys were in an accelerated development stage, while girls have eventually experienced such biological development before. Literature is consensual that girls overcome maturation two years earlier than boys (Malina \& Bouchard, 1991). However between skill-levels, within each gender, swimmers presented differences between them (i.e. a high intra-individual variability). Swimmers in skill-level 2 were characterized by a higher intra-individual variability (increase) in comparison to their skill-level 1 counterparts. These differences highlight the existent variability even in an age-group of swimmers, suggesting that each swimmer has a specific developmental rate.

Regarding hydrodynamics, mixed results were obtained. Both $\mathrm{D}_{\mathrm{a}}$ and $\mathrm{C}_{\mathrm{Da}}$ increased between $\mathrm{M} 1$ and $\mathrm{M} 7$ in both genders, except the $\mathrm{C}_{\mathrm{Da}}$ for boys and girls in skill-level 1 (decrease). Unchanged hydrodynamics was reported for eight weeks of training at the beginning of a season (Marinho et al., 2010). The main aim of this general period of preparation was to build-up aerobic capacity and aerobic power, enhancing swimming technique. However, one week of drill training with specific visual and kinaesthetic feedbacks, was enough to decrease $\mathrm{C}_{\mathrm{Da}}$ in pubescent swimmers (Havriluk, 2006). So, hydrodynamic enhancement is more related to technical ability than to energetic build-up. Indeed swimmers in skill-level 1 (both genders) did decrease their $\mathrm{C}_{\mathrm{Da}}$ (boys: $-0.30 \%$; girls: $-0.71 \%$ ). During the two-year assessment, the swimmers training included technical drills to enhance their hydrodynamic profile (i.e., optimizing their body and segments position while swimming). Nevertheless our data shows that those technical drills had a higher contribution to the fastest swimmers (skill-level 1) than on their counterparts in skill-level 2. These differences in technical ability parameters also highlight the intra-individual variability in an age-group of swimmers within each gender.

Overall, kinematics and efficiency increased (enhanced) between M1 and M7, but only the v showed a significant increase. The improvement of young swimmers' swimming velocity between two major competitions was reported as being related to SL increases and SF decreases (Tella et al., 2002). This SL-SR relationship is a result of growth (e.g. height, arm span, hands and feet dimensions). However, present data showed an increase in the SF for most groups (except girls' skill-level 1). It seems that at these early ages swimmers use both SF and SL to improve swimming velocity and therefore the performance. Skill-level 2 swimmers presented a higher amount of improvement. As these swimmers also showed a higher intra-individual variability in the anthropometrics, this highlights the influence of anthropometrics features in stroke mechanics. Nevertheless, kinematic and efficiency features presented a no-linear fashion way. In M2 swimmers were submitted to a heavy training period to build-up other determinant domains of performance (e.g. energetics). E.g. as we can learn from the swimmers sub-section, volume training per session was $4.86 \pm 0.97 \mathrm{~km}$. Hence, in M2, volume would be close to the upper limit of this confidence interval. However, one might not consider that this kind of energetic training comes with no downside. Stroke mechanics seems to impair due to it (for both genders' skill-levels), even so, performance in M2 was not affected for all conditions.

\section{Inter-individual variability}

Based on paired comparisons, a significant inter-individual variability was showed between skill-levels in both genders along the two seasons for the performance and most of the anthropometric features (except for the FSA, all conditions). On the other hand, hydrodynamics, kinematics and efficiency did not present the same trend. For both genders' skill-levels a no-significant inter-individual variability was observed in most moments. Yet the $\mathrm{v}$ and the SI did show a significant inter-individual variability between skill-levels (mainly on boys) in most of the moments in the two seasons. Therefore it can be stated that an inter-individual variability do exist within an agegroup of young swimmers, especially for the anthropometrics and some variables responsible for the stroke mechanics (i.e., v and SI). Silva et al. (2013) showed that pubertal swimmers (in both genders) do have higher standards in variables related to stroke mechanics (e.g., v and SL). However, literature does not report young swimmers' variability within an age-group or other kind in longitudinal researches. Previous studies (Lätt et al., 2009a, 2009b; Tella et al., 2002) assumed that swimmers in the same age-group share the same development pattern and that variance might be a residual error. However, new trends in swimming research suggest that each athlete has a unique development rate (Philips et al., 2010). In fact present data highlight that a swimmers' age-group is characterized by a significant inter-individual variability namely in anthropometric features, $\mathrm{v}$ (kinematics) and SI (efficiency). Indeed swimmers in skill-level 1 (both genders) were characterized by higher body dimensions, $\mathrm{v}$ and SI and hence a higher performance.

Inter-individual variability based on Cohen's Kappa quantifies the partial position of a swimmer against remaining contenders within a skill-level. A higher variability indicates that there are several changes in the partial position of the swimmers throughout the time-frame under analysis (Costa et al., 2012). Overall, performance showed a moderate $(0.40 \leq \mathrm{K}<0.75)$ and anthropometrics a high stability $(\mathrm{K} \geq 0.75$; i.e. a low inter-individual variability) for both genders' skill-levels. Contrarily, for hydrodynamics, kinematics and efficiency a high inter-individual variability was observed $(\mathrm{K}<0.40)$. These findings are of major importance as it also highlights the existent variability for technical ability patterns within a group of swimmers with similar characteristics. Especially in swimmers that are still suffering growth and maturation processes that influence the stroke mechanics. Moreover, each athlete should be seen as a unique individual and therefore one might consider that each one "chooses" their path to enhance performance. Nowadays adult/ elite research highlight that these individual changes should not be considered as residual variances (Costa et al., 2013). This perspective comes along with the state of the art about motor control and motor learning, that in terms of human movement, 
newer theories of movement control do not view variability in movements as error (i.e. dynamical systems theory). So, performance research should give a step forward towards this type of research framework.

\section{Conclusion}

We conclude that within an age-group of young swimmers a gender and skill-level effect was identified. Overall in both genders, swimmers in skill-level 2 presented a higher intra-individual variability. During the two seasons the performance and the anthropometric features were the ones presenting a significant inter-individual variability between skill-levels and also a moderate (performance) to high (anthropometrics) inter-individual variability within each skill-level. Therefore swimmers in the same age-group do differ between them, hence practitioners and coaches should design customized training plans for each swimmer and put more focus on individual and dynamic analysis frameworks.

\section{References}

Anderson, M., Hopkins, W., Roberts, A. \& Pyne, D. (2006). Monitoring seasonal and long-term changes in test performance in elite swimmers. European Journal of Sport Sciences, 6, 145-154.

Barbosa, T.M., Bragada, J.A., Reis, V.M., Marinho, D.A., Carvalho, C. \& Silva, A.J. (2010). Energetics and biomechanics as determining factors of swimming performance: Updating the state of the art. Journal of Science and Medicine in Sport, 13, 262-269.

Barbosa, T.M., Morouço, P.G., Jesus, S., Feitosa, W.G., Costa, M.J., Marinho, D.A., ... Garrido, N.D. (2013). The interaction between intra-cyclic variation of the velocity and mean swimming velocity in young competitive swimmers. International Journal of Sports Medicine, 34, 123-130.

Bideault, G., Herault, R., \& Seifert, L. (2013). Data modelling reveals inter-individual variability of front crawl swimming. Journal of Science and Medicine in Sports, 16, 281-285.

Craig, A., \& Pendergast, D. (1979). Relationships of stroke rate, distance per stroke and velocity in competitive swimming. Medicine and Science in Sports Exercise, 11, 278-283.

Costa, M.J., Bragada, J.A., Mejias, J.E., Louro, H., Marinho, D.A., Silva, A.J. \& Barbosa, T.M. (2012). Tracking the performance, energetics and biomechanics of international versus national level swimmers during a competitive season. European Journal of Applied Physiology, 112, 811-820.

Costa, M.J., Bragada, J.A., Mejias, J.E., Louro, H., Marinho, D.A., Silva, A.J. \& Barbosa, T.M. (2013). Effects of swim training on energetics and performance. International Journal of Sports Medicine, 34, 507-513.

Costill, D.L., Kovaleski, J., Porter, D., Kirwan, J., Fielding, R. \& King, D. (1985). Energy expenditure during front crawl swimming: predicting success in middle-distance events. International Journal of Sports Medicine, 6, 266-270.

Davids, K., Glazier, P., Araújo, D., \& Bartlett, R. (2003). Movement systems as dynamical systems: the functional role of variability and its implications for Sports Medicine. Sports Medicine, 33, 245-260.

Durand-Bush, N., \& Salmela, J. (2002). The development and maintenance of expert athletic performance: perceptions of World and Olympic champions. Journal of Applied Sport Psychology, 14, 154-171.
Havriluk, R. (2006). Magnitude of the effect of an instructional intervention on swimming technique and performance. In: J. P. Vilas -Boas, F. Alves, \& A. Marques (Eds.), X International Symposium of Biomechanics and Medicine in Swimming (pp. 218-220). Porto: Portuguese Journal of Sport Sciences.

Kolmogorov, S., \& Duplisheva, O. (1992). Active drag, useful mechanical power output and hydrodynamic force in different swimming strokes at maximal velocity. Journal of Biomechanics, 25, 311-318.

Landis, J., \& Koch, G. (1977). The measurement of observer agreement for categorical data. Biometrics, 33, 159-174.

Lätt, E., Jürimäe, J., Haljaste, K., Cicchella, A., Purge, P., \& Jürimäe, T. (2009a). Longitudinal development of physical and performance parameters during biological maturation of young male swimmers. Perceptual Motor Skills, 108, 297-307.

Lätt, E., Jürimäe, J., Haljaste, K., Cicchella, A., Purge, P. \& Jürimäe, T. (2009b). Physical development and swimming performance during biological maturation in young female swimmers. Collegium Antropologicum, 33, 117-122.

Malina, R.M., \& Bouchard, C. (1991). Growth, maturation and physical activity. Human Kinetics, Champaign: Illinois.

Marinho, D.A., Barbosa, T.M., Costa, M.J., Figueiredo, C., Reis, V.M., Silva, A.J. \& Marques, M.C. (2010). Can 8 weeks of training affect active drag in young swimmers? Journal of Sports Science and Medicine, 9, 71-78.

Minghelli, F. \& Castro, F. (2006). Kinematics parameters of crawl stroke sprinting through a training season. In: J. P. Vilas-Boas, F. Alves, \& A. Marques (Eds.), X International Symposium of Biomechanics and Medicine in Swimming (pp. 62-64). Porto: Portuguese Journal of Sport Sciences.

Morais, J.M., Jesus, S., Lopes, V., Garrido, N.D., Silva, A.J., Marinho, D.A. \& Barbosa, T.M. (2012). Linking selected kinematic, anthropometric and hydrodynamic variables to young swimmer performance. Pediatric Exercise Science, 24, 649-664.

Phillips, E., Davids, K., Renshaw, I. \& Portus, M. (2010). Expert performance in sport and the dynamics of talent development. Sports Medicine, 40, 271-283.

Saavedra, J.M., Escalante, Y., \& Rodríguez, F.A. (2010). A multivariate analysis of performance in young swimmers. Pediatric Exercise Science, 22, 135-151.

Silva, A.F., Figueiredo, P., Seifert, L., Soares, S., Vilas-Boas, J.P., \& Fernandes, R.J. (2013). Backstroke technical characterization of 11-13 year old swimmers. Journal of Sports Science and Medicine, 12, 623-629.

Tella, V., Llana, S., Madera, J. \& Navarro, F. (2002). Evolution of anthropometrical and kinematic parameters in young swimmers: a longitudinal study. In: K. E. Gianikellis (Ed.), Proceedings of the XX International Symposium on Biomechanics in Sports (pp. 64-67). Cáceres: University of Extremadura.

Vantorre, J., Seifert, L., Fernandes, R.J., Vilas-Boas, J.P., \& Chollet, D. (2010). Comparison of grab starts between elite and trained swimmers. International Journal of Sports Medicine, 31, 887-893.

Zamparo, P., Pendergast, D.R., Mollendorf, J., Termin, A., \& Minetti, A.E. (2005). An energy balance of front crawl. European Journal of Applied Physiology, 94, 134-144.

\section{Authors' note}

Jorge Estrela Morais and Pedro Forte are affiliated with the Department of Sport Sciences, Polytechnic Institute of Bragança. Jorge Estrela Morais is also affiliated with the Research Centre in Sports, Health and Human Development, Vila Real, Portugal. 
Mario J. Costa is affiliated with the Department of Sport Sciences, Polytechnic Institute of Guarda, and with the Research Centre in Sports, Health and Human Development, Vila Real, Portugal.

Mario C. Marques and Daniel A. Marinho are affiliated with the Department of Sport Sciences, University of Beira Interior, Covilhã, and with the Research Centre in Sports, Health and Human Development, Vila Real, Portugal.

Antonio J. Silva is affiliated with the Department of Sport Sciences, Exercise and Health, University of Trás-os-Montes and Alto Douro, Vila Real, and with the Research Centre in Sports, Health and Human Development, Vila Real, Portugal.

Tiago M. Barbosa is affiliated with the Nanyang Technological University, Singapore and with the Research Centre in Sports, Health and Human Development, Vila Real, Portugal.

\section{Corresponding author}

Jorge E Morais

Department of Sport Sciences, Polytechnic Institute of Bragança Campus Sta. Apolónia, Apartado 1101, 5301-856, Bragança, Portugal Phone: +351 273303000

Fax: +351273303135

E-mail: morais.jorgestrela@gmail.com

\section{Acknowledgments}

Jorge E. Morais would like to acknowledge to the Portuguese Science and Technology Foundation (FCT) for the PhD grant (SFRH/ $\mathrm{BD} / 76287 / 2011$ ). The authors wish to thank Marc Moreira (University of Trás-os-Montes and Alto Douro) for his help during data collection.

Manuscript received on April 14, 2014

Manuscript accepted on August 1, 2014

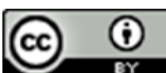

Motriz. The Journal of Physical Education. UNESP. Rio Claro, SP, Brazil - eISSN: 1980-6574 - under a license Creative Commons - Version 3.0 